\title{
EFFECT OF EFFERVESCENCE IN COMBINATION WITH SUPERDISINTEGRANTS IN THE FORMULATION OF PROPRANOLOL HCL ORAL DISINTEGRATING TABLETS
}

\author{
ASHOK THULLURU*, VEERAVALLI SAI KUMAR, PAVAN KUMAR M, ROSHITHA B \\ Department of Pharmaceutics, Sree Vidyanikethan College of Pharmacy, Tirupati-517 102, Chittoor Dist., A.P., India. \\ Email: ashokthulluru@gmail.com
}

Received: 09 November 2016, Revised and Accepted: 30 November 2016

\section{ABSTRACT}

Objective: The current research work is intended to formulate propranolol $\mathrm{HCl}$ (PLH) as orally disintegrating tablet (ODT). It is also intending to check the superiority in a combination of superdisintegrants and effervescent mixture than the use of superdisintegrants alone by a direct compression technique. To fasten the onset of action and thereby enhancing the bioavailability of PLH in comparison to its conventional tablets.

Methods: Standard calibration curve of PLH was obtained in pH 6.8 phosphate buffer by spectrophotometric method, drug-excipient compatibility studies were carried by Fourier transform infrared (FT-IR) studies. All the formulations were evaluated for pre and postcompression studies. Accelerated stability studies were carried out up to 6 months for the optimized formulation, $\mathrm{EF}_{3}$.

Results and Discussion: Superdisintegrants used in the study are compatible with PLH. Pre- and post-compression parameters were within the acceptable limits for all formulations. In vitro dissolution kinetic studies indicate the release of PLH from ODT increases as the concentration of superdisintegrants as well as the ratio of citric acid: $\mathrm{NaHCO}_{3}$ of effervescent mixture increases. Formulations with an effervescent mixture are having rapid disintegration and dissolution rate when compared to the formulations with superdisintegrants alone. The order of superdisintegrants in enhancing the dissolution rate of PLH is crospovidone (CPV) > croscarmellose sodium (CCS) > sodium starch glycolate (SSG). Formulation, $\mathrm{EF}_{3}$ (10\% CPV and 1:3, citric acid: $\mathrm{NaHCO}_{3}$ ratio, respectively) had the highest dissolution efficiency at 10 minutes $\left(\mathrm{DE}_{10}=82.74 \%\right)$; the first order dissolution rate constant $\left(\mathrm{K}_{1}=0.141 /\right.$ minutes $)$ with a regression coefficient $\left(\mathrm{r}^{2}=0.974\right)$ and lesser time for $90 \%$ of drug release $\left(t_{90}=4\right.$ minutes $)$, was considered as the optimal ODT in this study. Formulation $\mathrm{EF}_{3}$, passed the test for stability.

Conclusion: Hence, an effective PLH ODT was formulated by the direct compression technique with disintegration by combination of superdisintegrants and effervescent mixture, will fasten the onset of action and enhances the bioavailability of PLH in comparison to its conventional tablets.

Keywords: Propranolol HCl, Orally disintegrating tablet, Sodium starch glycolate, Croscarmellose sodium, Crospovidone, Direct compression, In vitro dissolution studies.

(C) 2017 The Authors. Published by Innovare Academic Sciences Pvt Ltd. This is an open access article under the CC BY license (http://creativecommons. org/licenses/by/4. 0/) DOI: http://dx.doi.org/10.22159/ajpcr.2017.v10i3.16096

\section{INTRODUCTION}

The most preferred route of administration of dosage forms is oral route, due to its potential advantages such as ease of administration, convenient dosing, self-medication, no pain, and patient compliance. Hence, tablets and capsules are the most popular dosage forms [1]. However, the important drawback of these dosage forms is dysplasia [2]. The abovementioned problem can be solved by developing a fast disintegrating/ dissolving drug delivery, i.e., oral disintegrating/dissolving tablet, disintegrates and dissolves rapidly in the saliva, Within a few seconds without the need of drinking water or chewing [3]. In pharmaceutical sciences, disintegration usually means the process by which a solid dosage form breaks up when it comes in contact with aqueous medium. This promotes the rapid release of drug and faster absorption too [4]. A rapid disintegration process is the prerequisite for a good bioavailability [5]. Orally disintegrating tablets (ODT) provides ease of administration, immediate action, convenient dosing, self-medication, no pain, and increases patient compliance [6]. The medications of fastacting, compliance critical, and pediatrics are commonly suitable for ODT [7]. Propranolol $\mathrm{HCl}$ (PLH) is a nonselective beta blocker, which blocks the action of epinephrine and norepinephrine on both $\beta 1$ - and $\beta 2$-adrenergic receptors. It has little intrinsic sympathomimetic activity but has strong membrane stabilizing activity. It is mainly used in the treatment of hypertension, supraventricular, tachyarrhythmia, ventricular arrhythmias, pheochromocytoma, thyrotoxicosis, and vascular headache. PLH is highly lipophilic and is almost completely absorbed after oral administration. However, it undergoes high first-pass metabolism by the liver and on average, only about $25 \%$ of PLH reaches the systemic circulation [8]. Clinically, orotransmucosal drug delivery is reported to be the most promising alternative approach for enhancing the bioavailability and fastening the onset of action in comparison to its conventional tablets because it has the high blood supply, a very thin membrane barrier (190 $\mu \mathrm{m})$, and an ability to bypass hepatic firstpass metabolism [9]. The properties of PLH, like low molecular weight $(295.81 \mathrm{~g} / \mathrm{mol})$; lesser oral dose (20-40 mg) and lesser biological halflife (3-5 h), makes it an ideal candidate, to select for the formulation of ODT $[10,11]$. This study was aimed to optimize the type and concentration of superdisintegrant by taking batches with $6 \%, 8 \%$, and $10 \% \mathrm{w} / \mathrm{w}$ of different superdisintegrants (crospovidone [CPV], croscarmellose sodium [CCS], and sodium starch glycolate [SSG] only); (i.e., batches from: $\mathrm{DC}_{1}$ to $\mathrm{DC}_{9}$ ) and to study the effect of the effervescent mixture in combination with superdisintegrants by taking batches with $10 \% \mathrm{w} / \mathrm{w}$ different superdisintegrants along with different ratios $(1: 1 ; 1: 2$, and $1: 3)$ of citric acid: $\mathrm{NaHCO}_{3}$, respectively (i.e., batches from: $\mathrm{EF}_{1}$ to $\mathrm{EF}_{9}$ ).

\section{MATERIALS AND METHODS}

\section{Materials}

PLH, SSG, CCS (Ac-DI-Sol), CPV (polyplasdone XL-10), citric acid, sodium bicarbonate $\left(\mathrm{NaHCO}_{3}\right)$, mannitol (PERLITOL-SD-200), aspartame, powder vanilla flavor, magnesium stearate, talc, and sodium lauryl sulfate (SLS) are received as gift samples from Richer Pharmaceuticals Ltd., Bengaluru, India. All the excipients used in the study are of pharmaceutical grade. 


\section{Methods}

Standard calibration curve of PLH in pH 6.8 phosphate buffer [9] Was obtained at the $\lambda_{\text {max }} 279 \mathrm{~nm}$ using an ultraviolet (UV)-visible spectrophotometer (UV-1700, Shimadzu, Mumbai, India) and represented in (Fig. 1). Which was further used for drug release calculations of in vitro dissolution studies and assay.

Drug-excipient compatibility/Fourier transform infrared (FTIR) studies [10]

FTIR studies were performed on drugand drug: Superdisintegrants (1:1). The samples were appropriately diluted with dried $\operatorname{KBr}(2 \mathrm{mg}$ sample in $200 \mathrm{mg} \mathrm{KBr}$ ) and crushed to make pellets under hydraulic pressure of

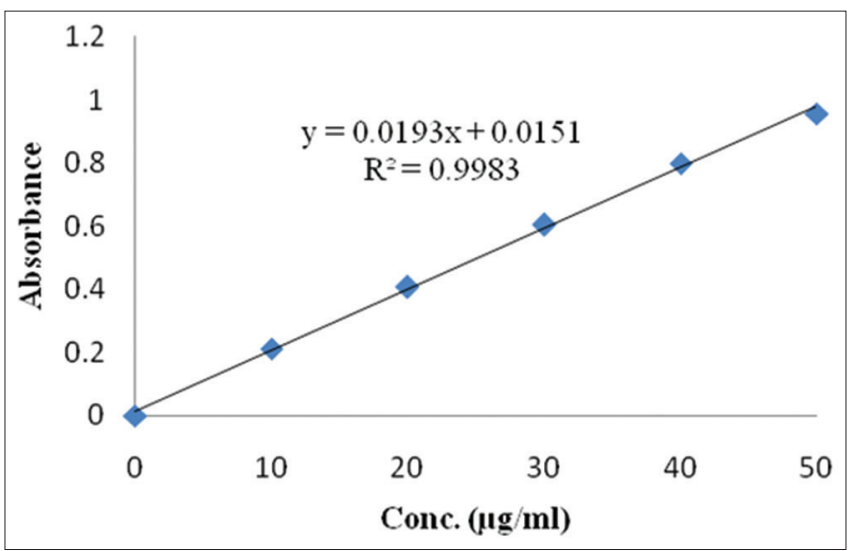

Fig. 1: Standard calibration curve of propranolol $\mathrm{HCl}$ in $\mathrm{pH} 6.8$ phosphate buffer
$600 \mathrm{~kg}$ and then the resulting pellets were subjected to analysis by an IR spectrophotometer (Shimadzu, FTIR 8700), in the region between 400 and $4000 / \mathrm{cm}$. FTIR spectra of pure PLH and drug: Superdisintegrants (1:1) samples were represented in Fig. 2.

\section{Preparation of PLH ODT [9]}

All the formulations were prepared by direct compression method by keeping the amount of PLH constant at $40 \mathrm{mg}$. The composition of other excipients is varied as mentioned in formulation tables (Tables 1 and 2). In these formulations SSG, CCS and CPV are used as superdisintegrants, mannitol as a directly compressible diluent, aspartame is an artificial sweetener, powder vanilla flavor as flavoring agent, magnesium stearate as a lubricant, talc as glidant, SLS as a surfactant solubility enhancer, citric acid, and $\mathrm{NaHCO}_{3}$ as effervescent mixture. PLH and all the other excipients excluding magnesium stearate and talc were co-sifted through Sieve No. \#40 (ASTM), blended uniformly in a poly bag for 10 minutes and lubricated with Sieve No. \# 60 (ASTM), passed magnesium stearate and talc and mixed in a poly bag for an additional 2-3 minutes. Tablets were compressed on a tabulating machine (16 station, Cadmach Pharma Machinery Pvt. Ltd., India) fitted with $8 \mathrm{~mm}$ standard round punches with an average weight of $200 \mathrm{mg}$ and hardness of $2-3 \mathrm{~kg} / \mathrm{cm}^{2}$.

\section{Precompression studies [12]}

The directly compressible tablet blends were evaluated for precompression studies.

\section{Angle of repose $(\theta)$}

Was determined by funnelling method. The blend was poured through the walls of a funnel, which was fixed at a position such that its lower tip was at a height of exactly $2 \mathrm{~cm}$ above hard surface. The blend was

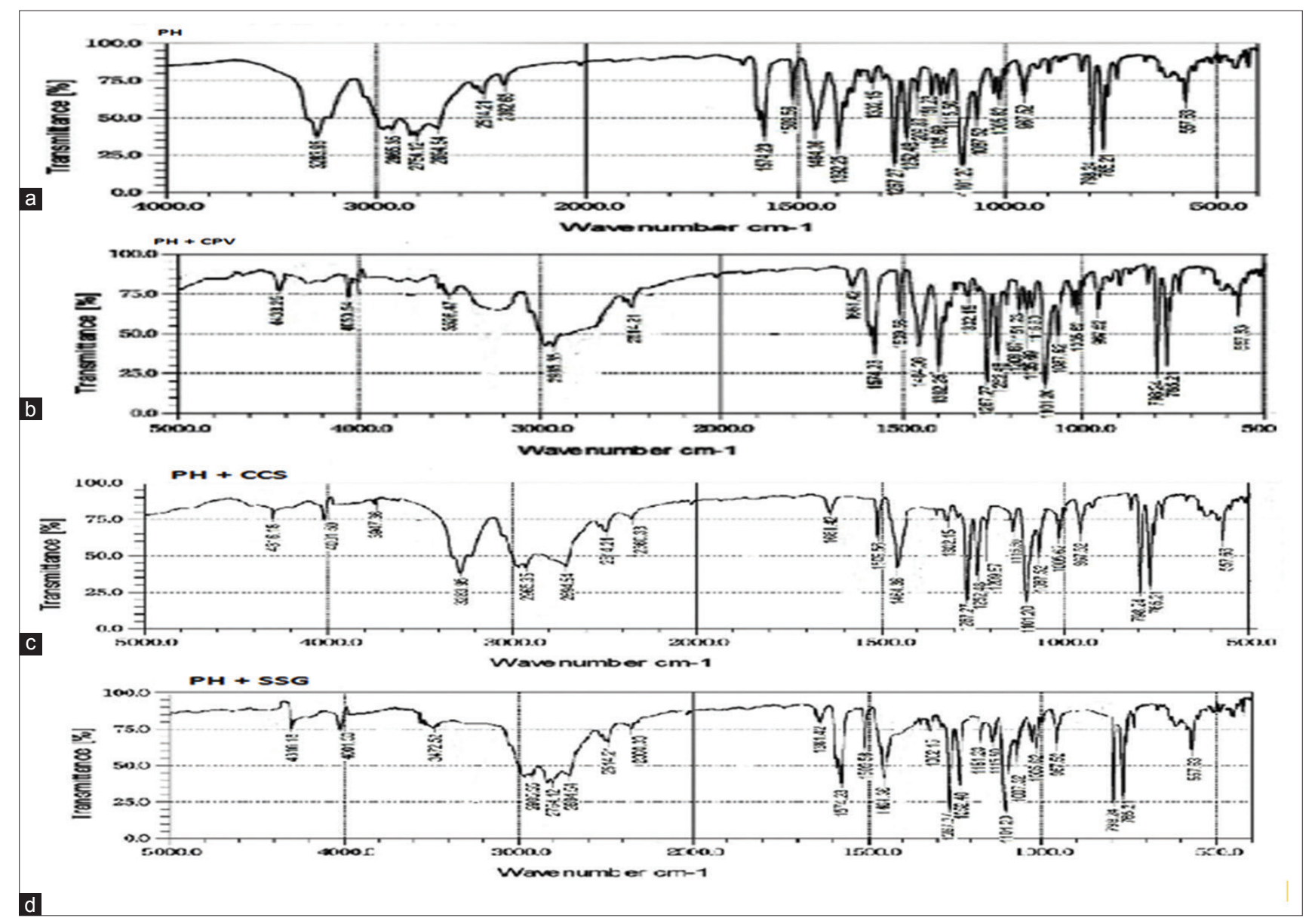

Fig. 2: Fourier transform infrared spectra of (a) propranolol $\mathrm{HCl}(\mathrm{PH})$, (b) $\mathrm{PH}+$ crospovidone, (c) $\mathrm{PH}+$ croscarmellose sodium and (d) PH+sodium starch glycolate 
Table1: Formulation table of PH ODT with superdintegrents alone

\begin{tabular}{|c|c|c|c|c|c|c|c|c|c|}
\hline$\% w / w$ superdisintegent & 6\% CPV & $8 \% \mathrm{CPV}$ & $10 \% \mathrm{CPV}$ & $6 \% \mathrm{CCS}$ & $8 \% \mathrm{CCS}$ & $10 \% \mathrm{CCS}$ & $6 \%$ SSG & $8 \%$ SSG & $10 \%$ SSG \\
\hline Ingredients* & $\mathrm{DF}_{1}$ & $\mathrm{DF}_{2}$ & $\mathbf{D F}_{3}$ & $\mathrm{DF}_{4}$ & $\mathbf{D F}_{5}$ & $\mathrm{DF}_{6}$ & $\mathrm{DF}_{7}$ & $\mathrm{DF}_{8}$ & $\mathrm{DF}_{9}$ \\
\hline $\mathrm{PH}$ & 40 & 40 & 40 & 40 & 40 & 40 & 40 & 40 & 40 \\
\hline CCS & - & - & - & 12 & 16 & 20 & - & - & - \\
\hline SSG & - & - & - & - & - & - & 12 & 16 & 20 \\
\hline Aspartame & 10 & 10 & 10 & 10 & 10 & 10 & 10 & 10 & 10 \\
\hline Powder vanilla flavor & 5 & 5 & 5 & 5 & 5 & 5 & 5 & 5 & 5 \\
\hline $\mathrm{CA}$ & - & - & - & - & - & - & - & - & - \\
\hline $\mathrm{NaHCO}_{3}$ & - & - & - & - & - & - & - & - & - \\
\hline SLS & 4 & 4 & 4 & 4 & 4 & 4 & 4 & 4 & 4 \\
\hline Talc & 6 & 6 & 6 & 6 & 6 & 6 & 6 & 6 & 6 \\
\hline Magnesium stearate & 6 & 6 & 6 & 6 & 6 & 6 & 6 & 6 & 6 \\
\hline Mannitol & 117 & 113 & 109 & 117 & 113 & 109 & 117 & 113 & 109 \\
\hline Total & 200 & 200 & 200 & 200 & 200 & 200 & 200 & 200 & 200 \\
\hline
\end{tabular}

*Quantity of ingredients per each tablet were expressed in Mg; average weight of a tablet is $200 \mathrm{mg}$. PH: Propranolol Hcl, ODT: Orally disintegrating tablet, CA: Citric Acid, CPV: Crospovidone, CCS: Croscarmellose sodium, SSG: Sodium starch glycolate, SLS: Sodium lauryl sulphate

Table 2: Formulation table of PH ODT with superdintegrents and effervescent mixture

\begin{tabular}{|c|c|c|c|c|c|c|c|c|c|}
\hline \multirow{2}{*}{$\begin{array}{l}\% \text { w/w superdisintegent } \\
\mathrm{CA} \mathrm{NaHCO}_{3}\end{array}$} & \multicolumn{3}{|c|}{$10 \% \mathrm{CPV}$} & \multicolumn{3}{|c|}{$10 \% \mathrm{CCS}$} & \multicolumn{3}{|c|}{$10 \%$ SSG } \\
\hline & $1: 1$ & $1: 2$ & $1: 3$ & $1: 1$ & $1: 2$ & $1: 3$ & $1: 1$ & $1: 2$ & $1: 3$ \\
\hline Ingredients* & $\mathrm{EF}_{1}$ & $\mathbf{E F}_{2}$ & $\mathrm{EF}_{3}$ & $\mathrm{EF}_{4}$ & $\mathbf{E F}_{5}$ & $\mathrm{EF}_{6}$ & $\mathbf{E F}_{7}$ & $\mathrm{EF}_{8}$ & $\mathbf{E F}_{9}$ \\
\hline $\mathrm{PH}$ & 40 & 40 & 40 & 40 & 40 & 40 & 40 & 40 & 40 \\
\hline CPV & 20 & 20 & 20 & - & - & - & - & - & - \\
\hline CCS & - & - & - & 20 & 20 & 20 & - & - & - \\
\hline SSG & - & - & - & - & - & - & 20 & 20 & 20 \\
\hline Powder vanilla flavor & 5 & 5 & 5 & 5 & 5 & 5 & 5 & 5 & 5 \\
\hline CA & 10 & 10 & 10 & 10 & 10 & 10 & 10 & 10 & 10 \\
\hline $\mathrm{NaHCO}_{3}$ & 10 & 20 & 30 & 10 & 20 & 30 & 10 & 20 & 30 \\
\hline SLS & 4 & 4 & 4 & 4 & 4 & 4 & 4 & 4 & 4 \\
\hline Talc & 6 & 6 & 6 & 6 & 6 & 6 & 6 & 6 & 6 \\
\hline Magnesium stearate & 6 & 6 & 6 & 6 & 6 & 6 & 6 & 6 & 6 \\
\hline Mannitol & 89 & 79 & 69 & 89 & 79 & 69 & 89 & 79 & 69 \\
\hline Total & 200 & 200 & 200 & 200 & 200 & 200 & 200 & 200 & 200 \\
\hline
\end{tabular}

*Quantity of ingredients per each tablet was expressed in mg; average weight of a tablet is $200 \mathrm{mg}$. PH: Propranolol Hcl, ODT: Orally disintegrating tablet, CA: Citric acid, CPV: Crospovidone, CCS: Croscarmellose sodium, SSG: Sodium starch glycolate, SLS: Sodium lauryl sulphate

poured till the time when the upper tip of the pile surface touched the lower tip of the funnel. The $\theta$ is calculated by the equation.

$\theta=\tan ^{-1} \mathrm{~h} / \mathrm{r}$

Where, $\theta=$ angle of repose, $\mathrm{h}=$ height of heap, and $\mathrm{r}=$ radius of the base of heap circle.

\section{Density}

Bulk density (BD)

A quantity of $2 \mathrm{~g}$ of blend from each formulation (previously lightly shaken to break any agglomerates formed) was introduced into a $10 \mathrm{~mL}$ measuring cylinder, and the volume is noted as bulk volume. The BD was calculated by the equation.

Bulk density=weight of powder/bulk volume

\section{Tapped density (TD)}

After the determination of BD, the measuring cylinder was fitted with a TD apparatus. The tapped volume was measured by tapping the powder for 500 times. Later the tapping was done for another 750 times, and the tapped volume was noted (the difference between these two volumes should be $<2 \%$ ). If it is more than $2 \%$, tapping is continued for another 1250 times, and the constant tapped volume was noted. The TD was calculated by the equation.
Tapped density=weigh of powder/tapped volume

Carr's index (CI): The percentage of $\mathrm{CI}$ is calculated by the equation.

CI=(tapped density-bulk density) $\times 100 /$ tapped density

Hausner's ratio (HR): Is a number that correlates to the flowability of powder. It is calculated by the equation.

HR=tapped density/bulk density

Precompression studies of all the formulations were carried out in triplicate; the consolidated results $($ mean $\pm \mathrm{SD}$ ) were tabulated in Table 3.

\section{Postcompression studies}

Tablet weight variation [12]

An electronic balance (Mettler Toledo, 3-MS-S/MS-L, Switzerland) was used to accurately weigh the individual weight of 20 tablets which were randomly selected from each formulation. The $($ mean $\pm S D)$ values were calculated.

\section{Friability test [12]}

The friability of the 20 tablets from each formulation was tested by a friabilator (ERWEKA, TAR 120, Germany) at a speed of $25 \mathrm{rpm}$ for 
Table 3: Precompression studies of propranolol HCl ODT

\begin{tabular}{|c|c|c|c|c|c|}
\hline F code & Angle of repose $(\theta)$ & $\mathrm{BD}\left(\mathrm{g} / \mathrm{cm}^{3}\right)$ & $\mathrm{TD}\left(\mathrm{g} / \mathrm{cm}^{3}\right)$ & Hausner's ratio & Carr's index (\%) \\
\hline $\mathrm{DC}_{1}$ & 31.08 & 0.528 & 0.692 & 1.31 & 23.69 \\
\hline $\mathrm{DC}_{2}$ & 30.78 & 0.541 & 0.652 & 1.21 & 17.02 \\
\hline $\mathrm{DC}_{3}^{2}$ & 31.92 & 0.530 & 0.614 & 1.16 & 13.68 \\
\hline $\mathrm{DC}_{4}^{3}$ & 29.53 & 0.538 & 0.639 & 1.18 & 15.80 \\
\hline $\mathrm{DC}_{5}$ & 29.62 & 0.512 & 0.621 & 1.21 & 17.55 \\
\hline $\mathrm{DC}_{6}$ & 30.12 & 0.521 & 0.630 & 1.21 & 17.30 \\
\hline $\mathrm{DC}_{7}$ & 28.17 & 0.543 & 0.640 & 1.17 & 15.15 \\
\hline $\mathrm{DC}_{9}^{8}$ & 30.09 & 0.534 & 0.682 & 1.27 & 21.70 \\
\hline $\mathrm{EF}_{1}$ & 30.68 & 0.540 & 0.633 & 1.17 & 14.69 \\
\hline $\mathrm{EF}_{2}$ & 29.18 & 0.543 & 0.652 & 1.21 & 16.71 \\
\hline $\mathrm{EF}_{3}^{2}$ & 29.72 & 0.531 & 0.611 & 1.15 & 15.06 \\
\hline $\mathrm{EF}_{4}^{3}$ & 29.32 & 0.572 & 0.670 & 1.17 & 14.62 \\
\hline $\mathrm{EF}_{5}^{4}$ & 27.71 & 0.552 & 0.689 & 1.24 & 19.88 \\
\hline $\mathrm{EF}_{6}{ }_{6}$ & 27.32 & 0.546 & 0.678 & 1.24 & 19.46 \\
\hline $\mathrm{EF}_{7}$ & 26.45 & 0.543 & 0.689 & 1.26 & 21.11 \\
\hline
\end{tabular}

ODT: Orally disintegrating tablet, BD: Bulk density, TD: Tapped density

4 minutes, the tablets were then de-dusted, reweighed, and percentage weight loss was calculated by the equation,

$\%$ friability=(initial weight-weight after friability) $\times 100$ /initial weight

Hardness test [12]

To evaluate the diametrical crushing strength, three tablets from each formulation were tested using a hardness tester (Monsanto type hardness tester, MHT-20, Campbell Electronics, India). The mean \pm SD values were calculated.

\section{Thickness [12]}

Of three tablets from each formulation was determined using a vernier caliper (Mitutoyo Corporation, Japan). The mean \pm SD values were calculated.

In vitro disintegration time and fineness of dispersion [13]

It is specified in the European Pharmacopeia (EP 6.0) that disintegration time determination procedure for ODT is same as that of conventional uncoated tablets and that the tablets should be dispersed within $<3$ minutes. The obtained tablet's dispersion was passed through a sieve screen with a nominal mesh aperture of $710 \mathrm{~mm}$ to confirm the fineness of dispersion. It was carried out in replicates of three tablets from each formulation and mean \pm SD values were calculated.

\section{Wetting time and water absorption ratio [14]}

A piece of tissue paper folded twice was placed in Petri dish having an internal diameter of $5.5 \mathrm{~cm}$, containing $6 \mathrm{~mL}$ of water. A tablet was placed on the paper and the time required for complete wetting was measured as wetting time, using a stopwatch. The wetted tablet was then reweighed and water absorption ratio (R) was determined using following equation.

Water absorption ratio $(\mathrm{R})=\left(\left[\mathrm{W}_{\mathrm{a}}-\mathrm{W}_{\mathrm{b}}\right] / \mathrm{W}_{\mathrm{b}}\right) \times 100$

Where, $\mathrm{W}_{\mathrm{b}}$ and $\mathrm{W}_{\mathrm{a}}$ were the weights of the tablet before and after water absorption.

Assay [9]

To evaluate the drug assay, three tablets from each formulation were powdered in motor and pestle. Blend equivalent to $1 \mathrm{mg}$ of PLH was accurately weighed and transferred into a $100 \mathrm{~mL}$ volumetric flask.
Then, the volume was made up to $100 \mathrm{~mL}$ with $\mathrm{pH} 6.8$ phosphate buffer and ultra-sonicated for 2 minutes to extract the PLH from the tablet blend and filtered through $0.45 \mu \mathrm{m}$ polytetrafluoroethylene (PTFE) filter disc, the filtrate was suitably diluted if necessary and its absorbance was measured by UV-visible spectrophotometer at $279 \mathrm{~nm}$.

Postcompression studies of all the formulations, except friability test were carried out in triplicate $(n=3)$; the consolidated results as $($ mean \pm SD) were tabulated in Table 4.

\section{In vitro dissolution studies [9]}

Were performed for three tablets form each formulation using the dissolution apparatus (Labindia Disso 2000, Labindia Analytical Instruments Pvt Ltd, India) with USP-II/paddle. Each dissolution flask contains $900 \mathrm{~mL}$ of $\mathrm{pH} 6.8$ phosphate buffer; speed of the paddle was maintained at $50 \mathrm{rpm}$; the temperature was kept stable at $37^{\circ} \mathrm{C} \pm 0.5^{\circ} \mathrm{C}$. At required time intervals, $5 \mathrm{~mL}$ of dissolution media was withdrawn with a pipette containing $0.45 \mu$ (PTFE) filter disc, suitably diluted if necessary and its absorbance was measured by UV-visible spectrophotometer at $279 \mathrm{~nm}$. Furthermore, $5 \mathrm{~mL}$ of fresh pH 6.8 phosphate buffer was replaced to the dissolution flask to keep the volume of dissolution medium constant. The dissolution profiles were represented graphically in Fig. 3 .

In vitro dissolution kinetics [15]

The in vitro drug release data were fitted into kinetic models to plot dissolution profiles (cum\% drug dissolved versus time) and first order plots ( $\log \%$ drug undissolved versus time) as per the following equations.

Zero order: $\mathrm{Q}_{\mathrm{t}}=\mathrm{Q}_{0}+\mathrm{K}_{0} \mathrm{t}$

First order: $\log Q_{t}=\log Q_{0}-K_{1} t / 2.303$

Where, $Q_{t}$ is the amount of the drug dissolved in time $t, Q_{0}$ is the initial amount of drug in the solution; $\mathrm{K}_{0}$ and $\mathrm{K}_{1}$ refers to the rate constants of zero and first order, respectively.

\section{In vitro dissolution kinetic parameters}

Dissolution efficiency at 10 minutes $\left(\mathrm{DE}_{10}\right)$ by trapezoid rule [16]; and time for $90 \%$ drug release $\left(\mathrm{t}_{90}\right)$ were calculated from dissolution profiles. Equations for calculating $\mathrm{DE}_{10}$ :

$[\mathrm{AUC}]_{\mathrm{t} 1}^{\mathrm{t} 2}=\frac{1}{2}\left(\mathrm{C}_{1}+\mathrm{C}_{2}\right)\left(\mathrm{t}_{2}-\mathrm{t}_{1}\right)$ 
Table 4: Postcompression studies of propranolol HCl ODT

\begin{tabular}{|c|c|c|c|c|c|c|c|c|}
\hline F code & $\begin{array}{l}\text { Weight } \\
\text { variation }\end{array}$ & $\begin{array}{l}\text { Hardness } \\
\left(\mathrm{kg} / \mathrm{cm}^{2}\right)\end{array}$ & Thickness (mm) & Friability* (\%) & $\begin{array}{l}\text { Wetting } \\
\text { time (seconds) }\end{array}$ & $\begin{array}{l}\text { In vitro } \\
\text { DT (seconds) }\end{array}$ & $\begin{array}{l}\text { Water absorption } \\
\text { ratio }(\%)\end{array}$ & Assay (\%) \\
\hline $\mathrm{DC}_{1}$ & $0.202 \pm 2.97$ & $2.8 \pm 0.24$ & $3.5 \pm 0.24$ & 0.74 & $50.00 \pm 0.01$ & $98.02 \pm 0.30$ & $6.21 \pm 0.61$ & $94.24 \pm 0.97$ \\
\hline $\mathrm{DC}_{2}$ & $0.205 \pm 0.97$ & $2.9 \pm 0.16$ & $3.5 \pm 0.48$ & 0.66 & $44.66 \pm 1.21$ & $90.12 \pm 1.53$ & $9.41 \pm 0.02$ & $95.68 \pm 0.48$ \\
\hline $\mathrm{DC}_{3}^{2}$ & $0.202 \pm 0.99$ & $2.7 \pm 0.24$ & $3.5 \pm 0.48$ & 0.49 & $42.66 \pm 1.77$ & $89.16 \pm 0.90$ & $13.82 \pm 0.53$ & $95.47 \pm 0.12$ \\
\hline $\mathrm{DC}_{4}^{3}$ & $0.204 \pm 1.47$ & $2.9 \pm 0.12$ & $3.4 \pm 0.97$ & 0.49 & $58.66 \pm 1.10$ & $117.20 \pm 1.33$ & $6.53 \pm 1.12$ & $94.24 \pm 0.44$ \\
\hline $\mathrm{DC}_{5}$ & $0.201 \pm 0.99$ & $2.8 \pm 0.12$ & $3.5 \pm 0.24$ & 0.49 & $54.66 \pm 2.21$ & $115.5 \pm 2.08$ & $8.11 \pm 1.55$ & $95.68 \pm 0.16$ \\
\hline $\mathrm{DC}_{6}^{5}$ & $0.207 \pm 0.48$ & $2.9 \pm 0.16$ & $3.5 \pm 0.97$ & 0.66 & $54.25 \pm 1.10$ & $102.34 \pm 0.88$ & $11.66 \pm 0.77$ & $96.47 \pm 0.48$ \\
\hline $\mathrm{DC}_{8}$ & $0.204 \pm 2.45$ & $2.7 \pm 0.24$ & $3.5 \pm 0.48$ & 0.82 & $56.33 \pm 0.87$ & $117.23 \pm 1.15$ & $4.86 \pm 0.99$ & $95.29 \pm 0.44$ \\
\hline $\mathrm{DC}_{9}$ & $0.203 \pm 1.47$ & $2.8 \pm 0.24$ & $3.5 \pm 0.48$ & 0.40 & $56.12 \pm 2.21$ & $113.09 \pm 2.10$ & $5.87 \pm 1.44$ & $94.66 \pm 1.12$ \\
\hline $\mathrm{EF}_{1}^{9}$ & $0.206 \pm 1.60$ & $2.6 \pm 0.16$ & $3.5 \pm 0.48$ & 0.25 & $16.66 \pm 1.12$ & $26.33 \pm 0.44$ & $23.31 \pm 2.42$ & $96.40 \pm 0.44$ \\
\hline $\mathrm{EF}_{2}$ & $0.202 \pm 1.68$ & $2.7 \pm 0.24$ & $3.5 \pm 0.24$ & 0.49 & $13.33 \pm 0.88$ & $22.00 \pm 1.33$ & $23.71 \pm 0.71$ & $97.73 \pm 1.12$ \\
\hline $\mathrm{EF}_{3}^{2}$ & $0.206 \pm 0.97$ & $2.7 \pm 0.24$ & $3.5 \pm 0.48$ & 0.41 & $11.00 \pm 1.12$ & $13.66 \pm 1.11$ & $25.39 \pm 5.12$ & $96.57 \pm 0.48$ \\
\hline $\mathrm{EF}_{4}^{3}$ & $0.206 \pm 0.58$ & $2.7 \pm 0.24$ & $3.5 \pm 0.79$ & 0.41 & $16.00 \pm 0.66$ & $29.66 \pm 0.88$ & $19.36 \pm 1.02$ & $95.69 \pm 1.11$ \\
\hline $\mathrm{EF}_{5}$ & $0.208 \pm 1.25$ & $2.8 \pm 0.24$ & $3.5 \pm 0.48$ & 0.33 & $19.00 \pm 0.66$ & $28.24 \pm 0.66$ & $21.35 \pm 2.45$ & $95.21 \pm 1.12$ \\
\hline $\mathrm{EF}_{6}^{5}$ & $0.202 \pm 1.13$ & $2.9 \pm 0.16$ & $3.4 \pm 0.48$ & 0.33 & $20.32 \pm 0.88$ & $27.00 \pm 1.33$ & $22.59 \pm 2.93$ & $96.02 \pm 0.12$ \\
\hline $\mathrm{EF}_{8}$ & $0.202 \pm 0.79$ & $2.7 \pm 0.24$ & $3.5 \pm 0.79$ & 0.49 & $23.00 \pm 0.66$ & $35.66 \pm 0.44$ & $20.74 \pm 2.25$ & $94.88 \pm 0.66$ \\
\hline $\mathrm{EF}_{9}^{8}$ & $0.204 \pm 0.58$ & $2.8 \pm 0.24$ & $3.5 \pm 0.79$ & 0.66 & $26.33 \pm 0.44$ & $34.66 \pm 1.78$ & $21.24 \pm 1.13$ & $97.57 \pm 0.66$ \\
\hline
\end{tabular}

*Except friability test all other were performed as $n=3$ and the values are given as mean \pm SD. ODT: Orally disintegrating tablet

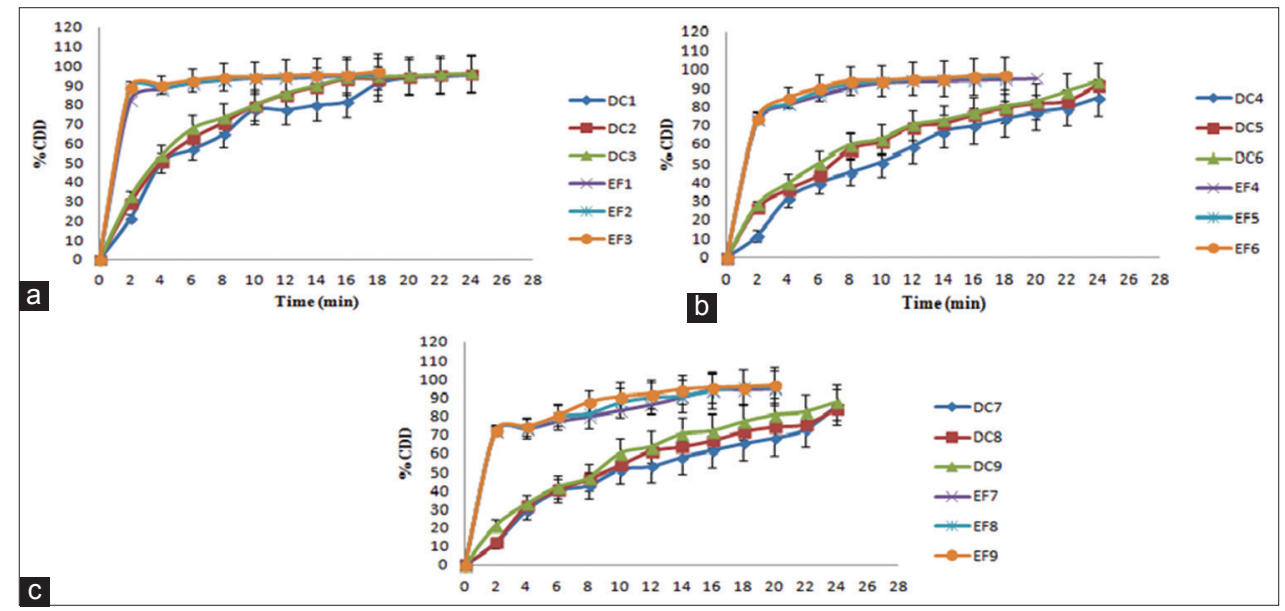

Fig. 3: In vitro disso profiles of propranolol $\mathrm{HCl}$ orally disintegrating tablet (a) with crospovidone, (b) with croscarmellose sodium and (c) with sodium starch glycolate

$[\mathrm{AUC}]_{0}^{10}=[\mathrm{AUC}]_{0}^{2}+[\mathrm{AUC}]_{2}^{4}+[\mathrm{AUC}]_{4}^{6}+[\mathrm{AUC}]_{6}^{8}+[\mathrm{AUC}]_{8}^{10}$

$\mathrm{DE}_{10}=\frac{[\mathrm{AUC}]_{0}^{10}}{\text { Total area at } 10 \text { minutes }} \times 100$

Where, $[\mathrm{AUC}]_{\mathrm{t} 1}^{\mathrm{t} 2}=$ Area under curve between time points $\mathrm{t}_{1}$ and $\mathrm{t}_{2}$

Total area at 10 minutes $=10 \times 100=1000 \mathrm{~cm}^{2}$

The first order dissolution rate constant $\left(\mathrm{K}_{1}\right)$ and regression coefficient $\left(\mathrm{r}^{2}\right)$ of the first order profiles were calculated from first order plots. The consolidated in vitro dissolution kinetic parameters of PLH ODT were tabulated in Table 5.

\section{Accelerated stability studies [17]}

Of the optimized formulation $\mathrm{EF}_{3}$, was carried out; by placing 20 tablets each in a 10 CC HDPE bottle; according to ICH guidelines in a humidity chamber (NSW-175, Narang Scientific Work, India) maintained at $45^{\circ} \mathrm{C} \pm 2{ }^{\circ} \mathrm{C}$ and $75 \% \pm 5 \%$ relative humidity up to 6 month. At the end of 1 month, 2 month, 3 month, and 6 month, the respective samples were withdrawn and evaluated for postcompression studies. The chemical stability of drug in the 6 month-accelerated stability sample of formulation $\mathrm{EF}_{3}$, was compared with the drug alone by FTIR studies (Shimadzu, FTIR 8700), recorded in the region of $400-4000 / \mathrm{cm}$, by $\mathrm{KBr}$ pellet method. The consolidated results of postcompression studies on accelerated stability samples of formulation $\mathrm{EF}_{3}$; except friability test were carried out in triplicate and the results as mean \pm SD were tabulated in Table 6. FTIR spectra of pure PLH and 6 month-accelerated stability sample of formulation $\mathrm{EF}_{3}$ were represented in Fig. 4. In vitro dissolution profiles of accelerated stability samples of formulation $\mathrm{EF}_{3}$ were represented graphically in Fig. 5.

\section{RESULTS AND DISCUSSION}

Standard calibration curve of PLH in pH 6.8 phosphate buffer Based on the measurement of absorbance at $279 \mathrm{~nm}$ in $\mathrm{pH} 6.8$ phosphate buffer in the concentration range of $10-50 \mu \mathrm{g} / \mathrm{ml}$, a straight line with an equation: $y=0.0193 x+0.0151$ and a regression coefficient $\left(r^{2}\right)$ of 0.9983 was obtained (Fig. 1).

\section{Drug-excipient compatibility/FTIR studies}

The FTIR spectrum of PLH showed a characteristic secondary amine - NH stretch at $3280 / \mathrm{cm}$, a C-H stretch at $2964 / \mathrm{cm}$, an aryl C $1 / 4 \mathrm{C}$ stretch at $1579 / \mathrm{cm}$, an aryl $0-\mathrm{CH}_{2}$ asymmetric stretch at $1240 / \mathrm{cm}$, an aryl $0-\mathrm{CH}_{2}$ symmetric stretch at $1030 / \mathrm{cm}$, and a peak at $798 / \mathrm{cm}$ due to alpha-substituted naphthalene. Comparison of FTIR spectra of pure drug with the drug: Superdisintegrant (1:1 ratio) samples indicate the 
absence of chemical interaction between PLH and superdisintegrants used in the study (Fig. 2).

\section{Precompression studies}

Of the directly compressible blends of all formulations, reveals that the angle of repose was found between $26^{\circ} 45^{\prime}$ and $31^{\circ} 92^{\prime}$, BD between 0.509 and $0.580 \mathrm{~g} / \mathrm{cm}^{3}$, TD between 0.611 and $0.703 \mathrm{~g} / \mathrm{cm}^{3}$, HR between 1.15 and 1.31 , and CI between $15.05 \%$ and $23.69 \%$. The micromeritic studies indicate better flow and compression characteristics of all the formulations. In these formulations sugar based excipient (Mannitol) is used as diluent, which impart good flow and compressibility to the directly compressible blends. It also exhibits the high aqueous solubility and sweetness, and hence, impart taste masking property and a pleasing mouth feel [18] (Table 3).

\section{Postcompression studies}

Of all the formulations, reveals that the weight variation of tablets was found to be $0.201-0.208 \%$. The average thickness of tablets was found to be 3.4-3.5 $\mathrm{mm}$. The average hardness of the tablets was $2.6-2.9 \mathrm{Kg} / \mathrm{cm}^{2}$, indicating satisfactory mechanical strength. The $\%$ weight loss in the friability test ranges from $0.25 \%$ to $0.82 \%$, which was $\mathrm{N}$-methyltryptamine $1 \%$ as per official requirement of Indian Pharmacopeia indicating a good mechanical strength of tablets. Assay of all the prepared batches is within $94.24-98.72 \%$ of the labeled content, indicating content uniformity of all the formulations. The wetting time of all the formulations was obtained in the range of 11.00-59.66 seconds. As the concentration of superdisintegrant increases, there is a significant decrease in the wetting time and in vitro disintegration time. Wetting is related to the inner structure of the tablets, hydrophilicity of the components and swelling mechanism of superdisintegrant. The water absorption ratio was related to the hydrophilicity of the matrix. This phenomenon was similar even with the combination of superdisintegrants with effervescent mixture in different ratios (1:1; $1: 2$, and $1: 3)$. The order of superdisintegrant's efficiency is CPV $>$ CCS $>$ SSG. The formulation $\mathrm{EF}_{3}$ (with $10 \%$ of $\mathrm{CPV}+1: 3$ ratio of citric acid: $\mathrm{NaHCO}_{3}$, respectively) which shows minutes wetting time of 11.00 seconds; minutes in vitro disintegration time of 13.66 seconds and max water absorption ratio of $25.39 \%$ is an optimized formulation (Table 4). Decrease in the wetting and disintegration times were clearly observed in formulations with a combination of superdisintegrants and effervescent mixture than the formulations with superdisintegrants alone. This is due to the synergistic effect of a combination of two approaches, namely superdisintegrants addition with effervescence approach. The evolved $\mathrm{CO}_{2}$ gas accelerated the breakdown of the tablets [19].

\section{In vitro dissolution studies}

Dissolution profiles are represented graphically in Figs. 1 and 2 indicate that the release rate increases with an increase in concentration of superdisintegrant. Based on the values of $\mathrm{K}_{1}$, the order of superdisintegrants in enhancing the dissolution rate of PLH in its ODT is ( $\mathrm{CPV}>\mathrm{CCS}>\mathrm{SSG}$ ). Formulations with a combination of superdisintegrants and effervescent mixture are having rapid disintegration and dissolution rate when compared to the formulations with superdisintegrants alone. A combination of two approaches, namely superdisintegrant addition with effervescence approach resulted in an increase in the drug dissolution rate, could be due to the synergistic effect of superdisintegrant and $\mathrm{CO}_{2}$ produced due to the wetting of the tablets. The evolved gas accelerated the breakdown of the tablets as indicated by their lesser disintegration times [19]. Dissolution rate also enhances with an increase in citric acid: $\mathrm{NaHCO}_{3}$ ratio of effervescent mixture $(1: 1<1: 2<1: 3)$ as it requires three molecules of sodium bicarbonate to neutralize one molecule of citric acid. Hence, the desired ratio of citric acid: $\mathrm{NaHCO}_{3}=1: 3.44$ by weight [20]. Formulation $\mathrm{EF}_{3}$ (with $10 \% \mathrm{CPV}$ AND 1:3, citric acid: $\mathrm{NaHCO}_{3}$ ratio,

Table 5: In vitro dissolution kinetics of propranolol $\mathrm{HCl}$ ODT

\begin{tabular}{|c|c|c|c|c|}
\hline F code & $t_{90}$ (minutes) & $\mathrm{DE}_{10}(\%)$ & First order dissolution rate constant; $K_{1}\left(\right.$ minutes $\left.^{-1}\right)$ & First order regression coefficient $\left(r^{2}\right)$ \\
\hline $\mathrm{DC}_{1}$ & 18 & 46.35 & 0.110 & 0.667 \\
\hline $\mathrm{DC}_{2}$ & 16 & 50.40 & 0.113 & 0.652 \\
\hline $\mathrm{DC}_{3}^{2}$ & 14 & 53.44 & 0.118 & 0.653 \\
\hline $\mathrm{DC}_{4}^{3}$ & $>24$ & 30.83 & 0.123 & 0.788 \\
\hline $\mathrm{DC}_{5}$ & 24 & 38.92 & 0.133 & 0.809 \\
\hline $\mathrm{DC}_{6}^{5}$ & 24 & 41.72 & 0.140 & 0.802 \\
\hline $\mathrm{DC}_{7}^{6}$ & $>24$ & 29.97 & 0.127 & 0.908 \\
\hline $\mathrm{DC}_{8}$ & $>24$ & 31.47 & 0.131 & 0.915 \\
\hline $\mathrm{DC}_{9}^{8}$ & $>24$ & 34.64 & 0.149 & 0.927 \\
\hline $\mathrm{EF}_{1}$ & 6 & 80.00 & 0.129 & 0.973 \\
\hline $\mathrm{EF}_{2}$ & 6 & 81.84 & 0.136 & 0.979 \\
\hline $\mathrm{EF}_{3}^{2}$ & 4 & 82.74 & 0.141 & 0.974 \\
\hline $\mathrm{EF}_{4}^{3}$ & 8 & 75.39 & 0.074 & 0.993 \\
\hline $\mathrm{EF}_{5}$ & 8 & 76.32 & 0.086 & 0.969 \\
\hline $\mathrm{EF}_{6}{ }_{6}$ & 6 & 77.86 & 0.094 & 0.966 \\
\hline $\mathrm{EF}_{7}^{6}$ & 14 & 68.83 & 0.064 & 0.935 \\
\hline $\mathrm{EF}_{8}$ & 14 & 69.89 & 0.068 & 0.982 \\
\hline $\mathrm{EF}_{9}^{8}$ & 10 & 71.92 & 0.080 & 0.993 \\
\hline
\end{tabular}

ODT: Orally disintegrating tablet

Table 6: Postcompression studies on accelerated stability samples of formulation $\mathbf{E F}_{3}$

\begin{tabular}{|c|c|c|c|c|c|}
\hline Parameter & Initial & $\begin{array}{l}45^{\circ} \mathrm{C} / 75 \% \mathrm{RH} \\
1 \text { month }\end{array}$ & $\begin{array}{l}45^{\circ} \mathrm{C} / 75 \% \mathrm{RH} \\
2 \text { month }\end{array}$ & $\begin{array}{l}45^{\circ} \mathrm{C} / 75 \% \mathrm{RH} \\
3 \text { month }\end{array}$ & $\begin{array}{l}45^{\circ} \mathrm{C} / 75 \% \mathrm{RH} \\
6 \text { month }\end{array}$ \\
\hline Weight variation (\%) & $0.206 \pm 0.97$ & $0.223 \pm 0.21$ & $0.241 \pm 0.32$ & $0.244 \pm 0.14$ & $0.252 \pm 0.52$ \\
\hline Hardness $\left(\mathrm{kg} / \mathrm{cm}^{2}\right)$ & $2.7 \pm 0.24$ & $2.6 \pm 0.12$ & $2.6 \pm 0.35$ & $2.5 \pm 0.12$ & $2.5 \pm 0.33$ \\
\hline Thickness (mm) & $3.5 \pm 0.48$ & $3.5 \pm 0.32$ & $3.5 \pm 0.11$ & $3.5 \pm 0.54$ & $3.5 \pm 0.43$ \\
\hline${ }^{*}$ Friability $(\% \mathrm{w} / \mathrm{w})$ & 0.41 & 0.43 & 0.51 & 0.53 & 0.50 \\
\hline Dissolution (seconds) & $11.00 \pm 1.12$ & $11.35 \pm 0.12$ & $12.35 \pm 0.34$ & $12.54 \pm 0.38$ & $12.55 \pm 0.42$ \\
\hline Wetting time (seconds) & $13.66 \pm 1.11$ & $14.12 \pm 0.13$ & $14.76 \pm 0.32$ & $14.23 \pm 0.45$ & $14.52 \pm 0.21$ \\
\hline Assay $(\%)$ & $96.57 \pm 0.48$ & $96.52 \pm 0.12$ & $96.40 \pm 0.44$ & $95.29 \pm 0.44$ & $94.66 \pm 1.12$ \\
\hline
\end{tabular}

*Except friability test all other were performed as $n=3$ and the values are given as mean \pm SD. RH: Relative humidity 


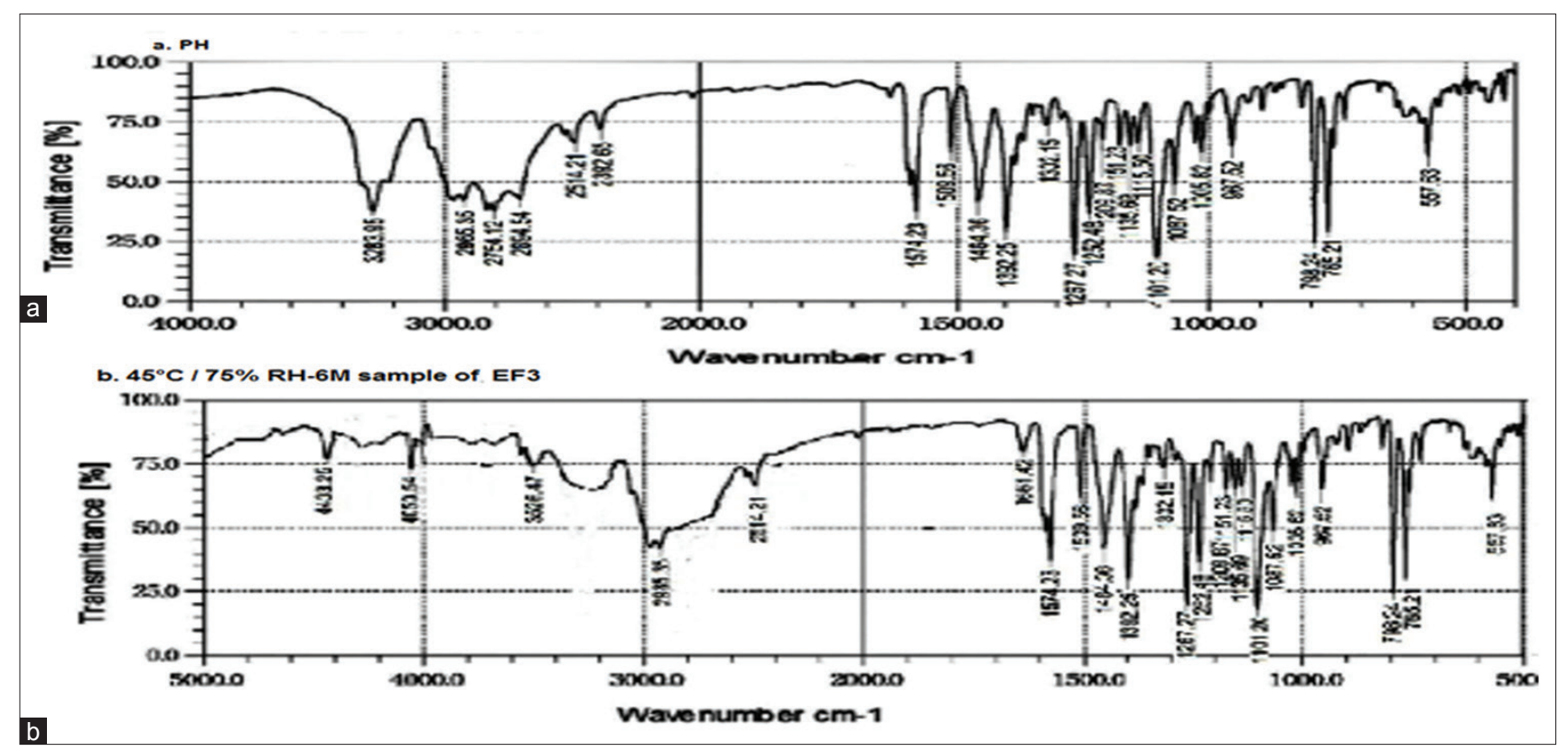

Fig 4: Fourier transform infrared spectra of (a) propranolol $\mathrm{HCl}$ and (b) $45^{\circ} \mathrm{C} / 75 \%$ relative humidity - 6 month sample of formulation $\mathrm{EF}_{3}$

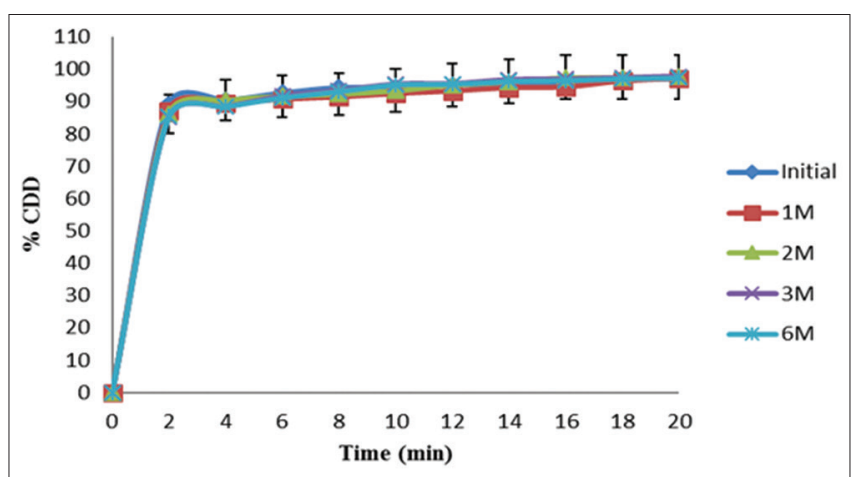

Fig. 5: Dissolution profiles of accelerated stability samples of formulation $\mathrm{EF}_{3}$

respectively) released $90 \%$ of drug within lesser time of 4 minutes than others, was considered as the optimal ODT (Fig. 3).

\section{In vitro dissolution kinetics}

Formulation $\mathrm{EF}_{3}$ had the highest $\mathrm{DE}_{10}(82.74 \%) ; \mathrm{K}_{1}(0.141 /$ minutes $)$ with $\mathrm{r}^{2}(0.974)$ and the lowest $\mathrm{t}_{90}(4$ minutes). Hence, it is the optimal ODT (Table 5).

\section{Accelerated stability studies}

As there were no significant differences in postcompression and in vitro dissolution profiles of initial and accelerated stability samples up to 6 months, formulation, $\mathrm{EF}_{3}$ passes the test for stability. FTIR spectrum of pure PLH is having primary amide group and two secondary amino groups. Two $\mathrm{N}-\mathrm{H}$ stretching bands resulting from symmetrical and asymmetrical stretching in $3400-3520 / \mathrm{cm}$ correspond to primary amide group [18]. An FTIR spectrum of 6 month-accelerated stability sample of optimized formulation $\left(\mathrm{EF}_{3}\right)$ shows the same functional groups at the corresponding frequencies as that of pure drug. This, indicates no significant chemical interaction and change in functional groups of PLH occurred during the accelerated stability study of optimized formulation, $\mathrm{EF}_{3}$ (Table 6, Figs. 4 and 5).

\section{CONCLUSION}

In the view of above findings, there is drug-excipient compatibility between PLH and superdisintegrants used in the study. All the formulations passed the pre- and post-compression parameters.
The release rate of PLH from ODT increases as the concentration of superdisintegrants as well as the ratio of citric acid: $\mathrm{NaHCO}_{3}$ of effervescent mixture increases. Formulations with an effervescent mixture are having rapid disintegration and dissolution rate when compared to the formulations with superdisintegrants alone. The order of superdisintegrants in enhancing the dissolution rate of PLH is $\mathrm{CPV}>\mathrm{CCS}>\mathrm{SSG}$. Formulation $\mathrm{EF}_{3}$ (with $10 \% \mathrm{CPV}$ and $1: 3$, citric acid: $\mathrm{NaHCO}_{3}$ ratio respectively) had the highest $\mathrm{DE}_{10}(82.74 \%)$; $\mathrm{K}_{1}(0.141 /$ minutes $)$ with $\mathrm{r}^{2}(0.974)$ and the lowest $\mathrm{t}_{90}$ (4 minutes), was considered as the optimal ODT. An accelerated stability study on $\mathrm{EF}_{3}$ in the final pack up to 6 months indicates it passed the test for stability. Therefore, an effective PLH ODT was formulated by the direct compression technique with disintegration attained by a combination of superdisintegrants and effervescent mixture. This PLH ODT will better manage the hypertension, by fastening the onset of action and enhancing the bioavailability of PLH in comparison to its conventional tablets.

\section{ACKNOWLEDGMENT}

The authors are thankful to Dr. M. Mohan Babu, Chairman, Sree Vidyanikethan Educational Institutions and Dr. C. K. Ashok Kumar, Principal, Sree Vidyanikethan College of Pharmacy, Tirupati- 517102; A.P.; India for providing us the required facilities and being a constant support to carry out this academic research.

\section{REFERENCES}

1. Sharma S, Gupta GD. Formulation and characterization of fast dissolving tablet of promethazine theoclate. Asian J Pharm 2008;2(1):70-2.

2. Siddiqui MN, Garima G, Sharma PK. Fast dissolving tablets: Preparation, characterization and evaluation. Int J Pharm Sci Rev Res 2010;4(2):87-96

3. Velmurugan $\mathrm{S}$, Vinushitha S. Oral disintegrating tablets: An overview. Int J Chem Pharm Sci 2010;1(2):1-12.

4. Guyot-Hermann AM. The disintegration and disintegrating agent. STP Pharm Sci 1992;2(6):445-62.

5. Colombo P, Caramella C, Conte U, Manna AL, Guyot-Hermann AM, Ringard J. Disintegrating force and tablet properties. Drug Dev Ind Pharm 1981;7:135-53.

6. Hirani JJ, Rathod DA, Vadalia KR. Orally disintegrating tablet: A review. Trop J Pharm Res 2009;8(2):161-72.

7. Ghosh T, Ghosh A, Prasad D. A review on new generation orodispersible tablets and its future prospective. Int J Pharm Pharm Sci 2011;3(1):1-7.

8. Available from: http://www.accessdata.fda.gov/drugsatfda_docs/ label/2011/016418s080,016762s017,017683s008lbl.pdf. 
9. Singh VK, Singh U, Raj T, Maurya JK, Choudhary N, Chauhan HS. Formulation and evaluation of MDT of propranolol $\mathrm{HCl}$ using different superdisintegrant. Am J PharmTech Res 2013;3(6):582-90.

10. Srikanth MV, Rao NS, Sunil SA, Ram BJ, Kolapalli VR. Statistical design and evaluation of a propranolol $\mathrm{HCl}$ gastric floating tablet. Acta Pharm Sin B 2012;2(1):60-9.

11. Derle D, Joshi O, Pawar A, Patel J, Jagadale A. Formulation and evaluation of buccoadhesive bi-layer tablet of propranolol hydrochloride. Int J Pharm Pharm Sci 2009;1(1):206-12.

12. Banker GS, Anderson NR, Lachman L, Liberman HA. The Theory and Practice of Industrial Pharmacy. $3^{\text {rd }}$ ed. Mumbai: Varghese Publishing House; 1987. p. 293-4.

13. EDQM. European Pharmacopeia. $6^{\text {th }}$ ed. Strasburg, France; EDQM Publications; 2007. p. 2435.

14. Comoglu T, Dogan A, Comoglu S, Basci N. Formulation and evaluation of diclofenac potassium fast-disintegrating tablets and their clinical application in migraine patients. Drug Dev Ind Pharm 2011;37(3):260-7.

15. Thulluru A, Ramesh KV, Dinakaran SK, Jana SK, Immanni R, Doddi P, et al. Formulation and evaluation of orally disintegrating tablet of Nimesulide. J Pharm Res 2012;5(6):3204-7.

16. Brahmankar D, Jaiswal SB. Biopharmaceutics and Pharmacokinetics: A Treatise. $2^{\text {nd }}$ ed. New Delhi: Vallabh Prakashan; 2009. p. 254-5.

17. Available from: http://www.ich.org/fileadmin/public web site/about ich/organisation/sadc/guideline_for_stability_studies.pdf.

18. Nagar P, Singh K, Chauhan I, Verma M, Yasir M, Khan A, et al. Orally disintegrating tablets: Formulation, preparation techniques and evaluation. J Appl Pharm Sci 2011;1(4):35-45.

19. Elkhodairy KA, Hassan MA, Afifi SA. Formulation and optimization of orodispersible tablets of flutamide. Saudi Pharm J 2014;22(1):53-61.

20. Patel HK, Chauhan P, Patel KN, Patel BA, Patel PA. Formulation and evaluation of effervescent tablet of paracetamol and ibuprofen. Int J Pharm Res Sch 2012;1(2):509-20. 